\title{
KEYS FOR THE IDENTIFICATION OF THE ADULTS OF GENUS CULEX (DIPTERA: CULICIDAE) IN SRI LANKA
}

\author{
F.P. AMERASINGHE \\ Department of Zoology, University of Peradeniya, Peradeniya.
}

(Received: 07 July 1995; accepted: 03 November 1995)

\begin{abstract}
Keys are provided for the identification of the aciult stages of 5 subgenera and 37 species of mosquitoes (Diptera: Culicidae) of the genus Culex occurring in Sri Lanka. These species are classified under the subgenera Culex (14 species), Culiciomyia (7 species),Eumelanomyia (5 species), Iophoceraomyia (9 species) and Lutzia (2 species).
\end{abstract}

Key words: Adults, Culex, keys for identification, mosquitoes, Sri Lanka.

\section{INTRODUCTION}

Genus Culex Linnaeus (Diptera: Culicidae) is represented by 37 valid species ciassified under 5 subgenera in Sri Lanka. ${ }^{1}$ It is second only to genus Aedes in terms of the number of species present in the island. Primary vectors of human diseases such as bancroftian filiariasis (eg., Cx. quinquefasciaius Say) ${ }^{2,3}$ and Japanese encephalitis ( $C x$. tritaeniorhynchus Giles, Cx. gelidus Theobald, and $C x$. fuscocephala Theobald), ${ }^{4}$ as well as potential vectors of these and other nematode and arboviral diseases occur among the representatives of genus Culex in Sri Lanka. ${ }^{3,5}$

There has been no previously published attempt to formulate keys for the identification of local Culex. However, recent taxonomic revisions of the genus have resulted in a number of publications that provide detailed species descriptions and subgenus or species-group based keys to the regional fauna, ${ }^{3,6,7-11}$ many species of which are represented in Sri Lanka. These taxonomic works are not easily available to local workers; moreover, they deal with a much larger fauna than is present in the islanc. The present paper, therefore, provides keys for the identification of the adult stage (male and female) of all known species of genus. Culex in Sri Lanka, as a guide to workers who need to identify species of this genus during the course of research or disease surveillance.

\section{METHODS AND MATERIALS}

The keys formulated herein were adapted from Barraud, ${ }^{12}$ Bram, ${ }^{6}$ Sirivanakarn, ${ }^{3,7,9}$ and Darsie \& Pradhan, ${ }^{13}$ whose works served as primary literature sources. Additional works consulted were Edwards, ${ }^{14}$ Thurman, ${ }^{15}$ Belkin, ${ }^{16}$ Sirivanakarn, ${ }^{8,10,11}$ and Reuben et al. ${ }^{17}$ Locally collected reference specimens deposited at the Department of Zoology, University of Peradeniya were used to check and validate characters used in the keys. Illustrations were drawn by the author. Scale bars on illustrations are in $\mathrm{mm}$. In relation to male genitalia illustrations, the terms dorsal, mesal etc. refer to the pre-rotation position of the genitalia. ${ }^{18}$ Reference to general illustrations appropriate fo: each 
key is provided immediately below each key heading, and specific illustrations are cited as required at specific key steps. The terminology used follows Harbach \& Knight: ${ }^{18}$

The keys have been prepared for use with specimens in reasonably good condition. Badly rubbed or damaged adults will be difficult to identify as important scales and setae, or appendages such as antennae, palps and legs will be missing. Wherever possible, the keys combine the characters of both adult sexes. Where such separation is incomplete, keys to males and females are provided separately. Male genitalia characters are used only where essential, since they usually require extensive dissection for adequate viewing. Separate keys to male genitalia are not provided because such keys are cumbersome and difficult to use, especially for Culex. ${ }^{19}$

The following species of genus Culex are treated in this work:

(a) Subgenus Culex Linnaeus: bitaeniorhynchus Giles, fuscocephala Theobald, gelidus Theobald, hutchinsoni Barraud, infula Theobald, jacksoni Edwards, mimulus Edwards, pseudovishnui Colless, quinquefasciatus Say, sinensis Theobald, sitiens Wiedemann, tritaeniorhynchus Giles, vishnui Theobald, whitmorei (Giles). (b) Subgenus Culiciomyia Theobald: bahri (Edwards), bailyi Barraud, fragilis Ludlow, nigropunctatus Edwards, pallidothorax Theobald, scanloni Bram, spathifurca (Edwards). (c) Subgenus Eumelanomyia Theobald: brevipalpis (Giles), campilunati Carter \& Wijesundara, castrensis Edwards, malayi (Leicester), pluvialis Barraud. (d) Subgenus Lophoceraomyia Theobald: bicornutus (Theobald), infantulus Edwards, lasiopalpis Sirivanakarn, mammilifer (Leicester), minutissimus (Theobald), quadripalpis (Edwards), rubithoracis (Leicester), uniformis (Theobald), wardi Sirivanakarn. (e) Subgenus Lutzia Theobald: fuscanus Wiedemann, halifaxii Theobald.

\title{
KEYS TO ADULTS OF GENUS CULEX IN SRI LANKA (A) KEY TO SUBGENERA OF CULEX
}

\author{
(Refer Figs. 1A-D, 2A-C, 3A-B, 4F and 5H)
}

1. Lower mesanepimeral area with 4 or more strong setae (note presence of alveoli if setae missing); relatively large species (wing length $4-5 \mathrm{~mm}$ ) Lutzia

Lower mesanepimeral setae absent or 1-2 weak setae present (Fig. 1D); small to moderate sized species (wing length less than $4 \mathrm{~mm}$ )

2(1). Pleuron with distinct scale patches at least on upper and lower mesokatepisternum and anterior mesanepimeron (Fig. 3A,B) Culex

Pleuron without distinct scale patches 
3(2). Acrostichal setae (Fig. 2A) well developed; male palpus

less than 0.25 length of proboscis (in part) Eumelanomyia

Acrostichal setae not well developed except at anterior promontory and rarely near prescutellar space; male palpus greater than 0.25 length of proboscis 4

4(3). Lower mesanepimeral seta absent; decumbent scales on occiput narrow. (in part) Eumelanomyia

Lower mesanepimeral seta present; decumbent scales on occiput broad, if only on ocular line

5(4). Scutal scaling very dense, smooth in appearance; palpal segment III of male with ventro-lateral linear series of lanceolate scales (Fig. 1C); male antenna without specialized scales or setae Culiciomyia

Scutal scaling sparse, rough in appearance; palpal segment III of male without ventrolateral lanceolate scales; male antenna with specialized scales and setae at least on flagellomeres 7 and 8 (Fig. 4F, 5H) Lophoceraomyia

\section{(B) KEY TO SPECIES OF SUBGENUS CULEX}

(Refer Figs. 1A-D, 2A-E, and 3A-H)

1. One or 2 lower mesanepimeral setae present (Fig. 1D); proboscis without distinct median pale ring (Fig. 1B,C); tarsomeres without pale bands at joints

Lower mesanepimeral setae absent; proboscis with distinct median pale ring (Fig. 3G,H); tarsomeres with pale bands at joints (Fig. 2C)

2(1). Abdominal terga with basal pale bands (Fig. 2B); pleuron with or without pattern of dark and pale areas

Abdominal terga unbanded; pleuron with striking pattern of dark integument and pale scale patches

(Fig. 3B) fuscocephala

3(2). Scutal integument reddish brown; pleural integument with distinct dark and pale areas on mesokatepisternum and mesanepimeron hutchinsoni

Scutal integument yellowish or pale brown; pleural integument without pattern of dark and pale areas (Fig. 3A) quinquefasciatus 
4(1). Wing with pattern of pale spots or streaks on at least 2 areas of costa and one area of other veins (Fig. 2E)

Wing without pattern of pale spots or streaks as above (Fig. 2D)

5(4). First (median) costal pale spot of wing involving veins

$S c$ and/or $C$ only; basal pale bands on abdominal terga broad, at least 0.25 segment length jacksoni

First (median) costal pale spot of wing involving veins $C, S c$ and $R 1$, sometimes $R s, M$ and $C u$ (Fig. 2E); basal pale bands on abdominal terga narrow, less than 0.25 segrnent length mimulus

6(4). Abdominal terga II-VI with complete apical or apical and basal pale bands

Abdominal terga II-VI with complete basal pale bands only

7(6). Wing with dark scales on all veins; hind-tarsomeres with pale bands at bases longer than those at apices sinensis

Wing with mixed pale and dark scales; hind-tarsomeres with apical and basal pale bands about the same length

8(7). Anterior 0.7 of scutum with pale scales contrasting sharply with dark scales on posterior 0.3 (Fig. $3 \mathrm{C}$ ); wing sparsely or heavily speckled with pale scales

Scales on scutum entirely dark; wing sparsely speckled with pale scales, usually limited to basal $0.5-0.75$ of veins $C, S c, R$, and $C u$ infula (dark form)

9(8). Wings heavily speckled with pale scales; abdominal terga speckled with pale scales; abdominal terga II-IV with broad apical pale bands bitaeniorhynchus

Wings sparsely speckled with pale scales, usually limited to basal $0.5-0.75$ of veins $C, S c, R$, and $C u$; abdominal terga not speckled with pale scales; abdominal terga II-IV without complete apical pale bands in female infula (light form)

10(6). Erect scales on centre of vertex whitish; anterior 0.7 of scutum covered with pure white scales (Figs. 3C,D)

Erect scales on centre of vertex pale yellow, dingy white or dark; anterior 0.7 of scutum covered with beige, yellow, golden or dark scales 
11(10). Wiite-scaled area of scutum ending at level of wing root, dark-scales posterior to that (Fig. 3C); anterior surface of fore- and midfemora without pale speckling (Fig. 3F); wing veins $R 1, R 4+5$, and $C u$ with narrow scales (Fig. 2D) gelidus

White-scaled area of scutum extending to scutellar margin in 4 lines (Fig. 3D); anterior surface of fore- and midfemora speckled with pale scales (Fig. $3 \mathrm{E}$ ); wing veins $R 1, R 4+5$, and $\mathrm{Cu}$ with broad scales whitmorei

12(10). Anterior gurface of fore- and midfemora with speckling of pale scales (Fig. 3E); abdominai terga sometimes with incomplete apical pale bands or patches in middle

sitiens

Anterior surface of fore- and midfemora dark, without sneckling of pale scales (Fig. 3F); abdominal tergal apical pale bands or patches entirely absent

13(12). Erect scales on vertex (Fig. 3G) and scales on anterior

0.7 of scutum mostly dark brown; male: segment 3 of maxillary palpus with row of dark, fine, hair-like setae on ventral surface tritaenioirhynchus

Erect scales on vertex pale beige or yellow in centre, darker posterolaterally (Fig. $3 \mathrm{H}$ ); scalés on anterior 0.7 of scutum mainly pale beige or yellow with mottling of some brown scales; male: segment 3 of maxillary palpus with row of flattened, scale-like setae on ventral surface (Fig. 1C)

14(13). Erect scales on vertex pale beige or yellowish white in centre, contrasting sharply with dark posterolateral scales; scutum with yellow to silvery scales; femora and proboscis never speckled with pale scales; male: proboscis without ventral tuft of hairs at base of median pale ring pseudovishnui

Erect scales on vertex dull yellow to golden brown, not contrasting sharply with brownish posterolateral scales; scutum with pale and dark scales mixed to varying degrees; femora and proboscis sometimes speckled with pale scales; male: proboscis with veritral tuft of hairs at base of median pale ring . sishnui

\section{(C) KEY TO SPECIES OF SUBGENUS CULICIOMYIA - FEMALES}

(Refer Figs. 1D, 2B, 2D, 4A and 4B)

1. Abdominal terga unbanded 2

Abdominal terga with basal pale bands or basal and

apical bands (Fig. 2B) 
2(1). Scales on all wing veins relatively short, about 5 times as long as broad fragilis

Scales on wing veins $R 2, R 3, M 1+2$ relatively long; about 7-10 times as long as broad bahri scanloni spathifurca

3(1). Pleural integument uniformly pale brown or with a faint brown stripe from anterior pronotal lobe to upper mesanepimeron bailyi

Pleural integument with distinct dark markings 4

4(2). Prominent black or very dark brown spot on upper mesanepimeral integument; light brown spot usually present on upper mesokatepisternum (Fig. 4A) nigropunctatus

Prominent black or brown spots not present on mesanepimeron or upper mesokatepisternum (Fig. 4B) pallidothorax

\section{(D) KEY TO SPECIES OF SUBGENUS CULICIOMYIA - MALES}

$$
\text { (Refer Figs. 1D, 2B, 2D, 5A-C) }
$$

1. Gonostylus divided proximally into an expanded, distally . denticulate external arm and a slender, pointed, sigmoid internal arm (Fig. 5B) spathifurca

Gonostylus undivided (Fig. 5A,C) 2

2(1). Convex surface of gonostylus without a crest of apical spines

(Fig. 5A) bailyi

Convex surface of gonostylus with apical crest of at least 3 recurved spines (Fig. 5C)

3(2). Abdominal terga unbanded

Abdominal terga with distinct basal pale bands

(Fig. 2B)

4(3). Scales on all wing veins relatively short, about 5 times as long as broad fragilis

Scales on wing veins $R 2, R 3, M 1+2$ relatively long, about 10 times as long as broad 
5(3). Pleural integument with prominent black or very dark brown spot present on upper mesanepimeron; subapical lobe of gonocoxite with leaf-like seta very broad. nigropunctatus

Pleural integument without prominent black or very dark brown spot on upper mesanepimeron; subapical lobe of gonocoxite with leaf-like seta long, pointed, and striated.... pallidothorax

(E) KEY TO SPECIES OF SUBGENUS EUMELANOMYIA - FEMALES

(Refer Figs. 1A, 1D, 2A)

1. Lower mesanepimeral and acrostichal bristles present (note presence of alveoli if missing) (Fig. 1D, 2A) 2

Lower mesanepimeral and acrostichal bristles absent brevipalpis

2(1). Decumbent scales on anterior dorsal margin of vertex broad, scales on central part of vertex broad or narrow

Decumbent scales on anterior dorsal margin and on centre of vertex entirely narrow castrensis

3(2). Central part of vertex with broad, ovate decumbent scales. malayi

Central part of vertex with narrow, linear decumbent scales. pluvialis campilunati

(F) KEY TO SPECIES OF SUBGENUS EUMELANOMYIA - MALES

(Refer Figs. 1C, 4C, 4D, 5A, 5D and 5E)

1. Palpus 0.75 length of proboscis, segments 3-5 thick, irregular or distorted in shape (Fig. 4C) brevipalpis

Palpus about 0.2 of proboscis length, segments 3-5 uniformly thin (Fig. 4D)

2(1). Normal flagellar whorls weakly plumose, with10-25 hairs; distal division of subapical lobe of gonocoxite without broad, spatulate or club-shaped leaflets castrensis

Normal flagellar whorls strongly plumose, with 30-40 hairs; distal division of subapical lobe of gonocoxite with broad, spatulate or club-shaped leaflets

3(2). Gonostylus bifurcate (Fig. 5D) malayi

Gonostylus simple, sickle-shaped 
4(3). Apex of gonocoxite with 6-7 strong setae sternally; paraproct crown mainly with coarse spicules campilunati

Apex of gonocoxite with 1-2 strong setae sternally; paraproct crown with a few coarse and several fine spine-like spicules pluvialis

(G) KEY TO SPECIES OF SUBGENUS LOPHOCERAOMYIA - FEMALES

(Refer Figs. 1A, 1D, 2B, 2D, 2F)

1. Decumbent scales on dorsum of vertex mainly broad; scales on wing veins $R 2$ and $R 3$ usually broad, clavate; abdominal terga sometimes with basolateral pale spots or pale bands

Decumbent scales on dorsum of vertex mainly narrow, linear; scales on wing veins $R 2$ and $R 3$ narrow, linear; abdominal terga completely dark, without pale markings

2(1). Abdominal terga entirely dark or with small basolateral pale spots

Abdominal terga with basal pale bands minutissimus infantulus

3(2). Thoracic integument yellowish, orange or golden; lower mesanepimeral seta absent; cibarial armature with about 30 teeth; wing length $2.0-2.7 \mathrm{~mm}$ rubithoracis

Thoracic integument dark brown; 1-2 lower mesanepimeral setae present (note presence of alveolus if seta missing); cibarial armature with about 60 teeth; wing length $3.0-4.0 \mathrm{~mm}$ quadripalpis

4(1). Lower mesanepimeral seta present (note presence of alveolus if seta missing)

Lower mesanepimeral seta absent uniformis lasiopalpis

5(4). Vertex with narrow, linear, pale decumbent scales along upper eye margin bicornutus

Vertex with broad, ovate, pale, decumbent scales along upper eye margin wardi 
(H) KEY TO SPECIES OF SUBGENUS LOPHOCERAOMYIA - MALES

\author{
(Refer Figs. 4E, 4F, 5A, 5E-H)
}

1. Antennal pedicel without spiculose prominence on inner dorsal surface; modified setal tufts on antennal flagellomeres 7-8 or 5-10 (Fig. 4F, 5H); genitalia: dorsal arm of lateral plate of phallosome present as slender, simple, apical beak-like process projecting tergally (Fig. $5 \mathrm{~F}$ ); paraproct crown relatively small

Antennal pedicel with spiculose prominence on inner. dorsal surface (Fig. 4E); modified setal tufts on fiagellomeres 5-8 or 5-9 (Fig. 5H); genitalia: dorsal arm of lateral plate of phallosome with partially denticulate or tuberculate external and simple spine-like internal processes (Fig. 5G); paraproct crown large (Fig. 5E)

2(1). Antennal flagellomeres 7-8 with inconspicuous mesal tufts of modified, spine-like or bristle-like setae (Fig. 4F); genitalia: subapical lobe of gonocoxite without leaflets

Antennal flagellomeres 5-10 with distinct lateral, ventral and mesal tufts of modified scales and setae (Fig. $5 \mathrm{H})$; genitalia: subapical lobe of gonocoxite with 1-2 leaflets

3(2). Dorsal beak-like arm of phallosome short, stout, simple (Fig. 5F); paraproct crown with 4-6 pale tooth-like spicules

minutissimus

Dorsal beak-like process of phallosome long, slender and strongly imbricate with reticules; paraproct crown with more than 20 dark spine-like spicules infantulus

4(2). Modified tuft of antennal flagellomere 5 with narrow, flattened, fine-tipped setae only; gonocoxite with a row of 3 submarginal setae rubithoracis

Modified tuft of antennal flagellomere 5 with broad dark scales and fine-tipped flat setae; gonocoxite with a row of 7-8 sub marginal setae quadripalpis

5(1). Palpal segments 2,3 with prominent lateral rows of numerous fine hair-like setae lasiopalpis

Palpal segments 2,3 without prominent lateral rows of fine hair-like setae 
6(5). Proboscis distinctly swollen from 0.2 - 0.5 the distance from base, with many prominent setae on lateral and ventral surfaces of swollen part; internal process of phallosome short, not projecting beyond apex of external process; external process with small, elongate, spiculose apical lobe (Fig. 5G) bicornutus

Proboscis not swollen as above; internal process of phallosome long, reaching or projecting beyond apex of external process; external process with broad spiculose or denticulate apical lobe 7

7(6). Antennal flagellomere 9 without a tuft of modified setae uniformis

Antennal flagellomere 9 with a tuft of modified bristle-like setae 8

8(7). Palpus shorter or subequal to proboscis length, palpal segments 4,5 shortened, segment 4 about 0.5 length of segment 5 ; inner surface of gonocoxite with 10-12 strong submarginal setae; gonostylus with distinct hump on dorsal margin, and with distinct dorsal subapical crest of strong spicules wardi

Palpus distinctly longer than proboscis, palpal segments 4,5 normal, subequal; inner surface of gonocoxite with 5-8 strong, sinuous submarginal setae; gonostylus slender, without hump on dorsal margin, with fine spicules on subapical dorsal surface mammilifer

\section{(I) KEY TO SPECIES OF SUBGENUS LUTZIA}

(Refer Figs. 1B, 1C, 2B)

1. Abdominal terga entirely dark, or all with apical pale bands of approximately the same width; median pale band of proboscis narrow, most prominent on ventral surface halifaxii

Abdominal terga V-VIII entirely pale-scaled or with very broad apical pale bands; terga II-IV entirely dark or with very narrow apical pale bands; median pale band of proboscis broad, clearly encircling it fuscanus 

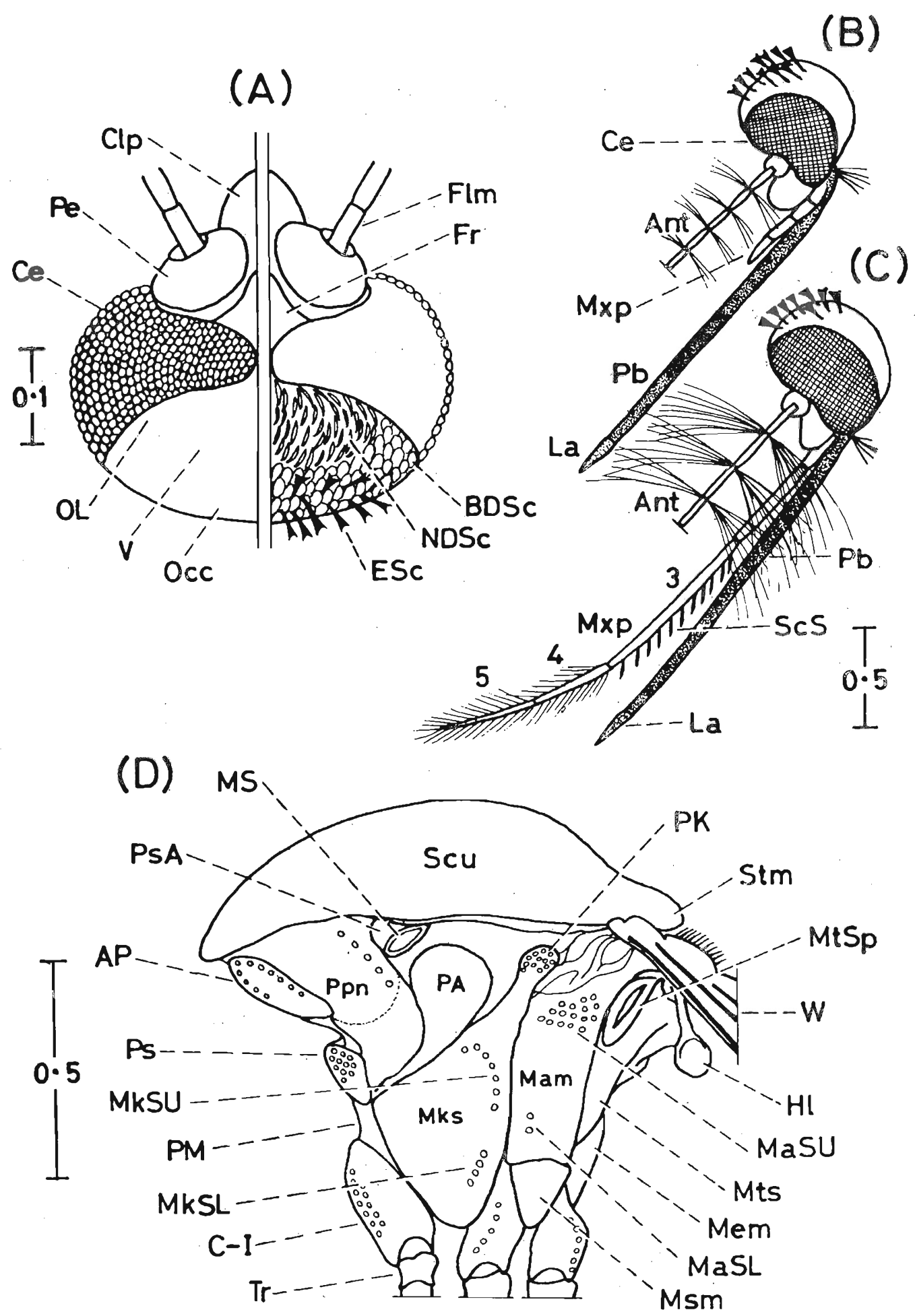
Figure 1: Generalized diagrams of a Culex mosquito. (A) Dorsal aspect of head; (B) lateral aspect of female head; (C) lateral aspect of male head; (D) lateral aspect of thorax.
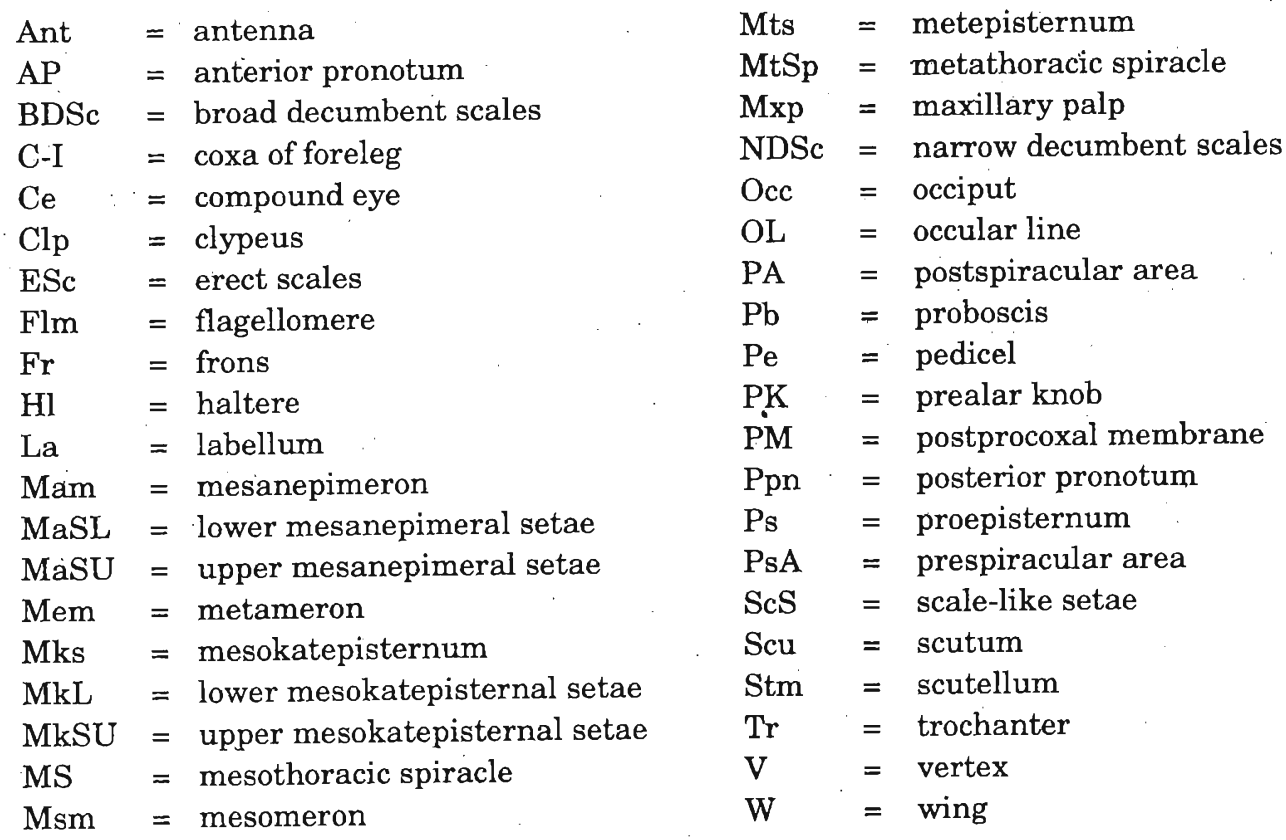

(A)

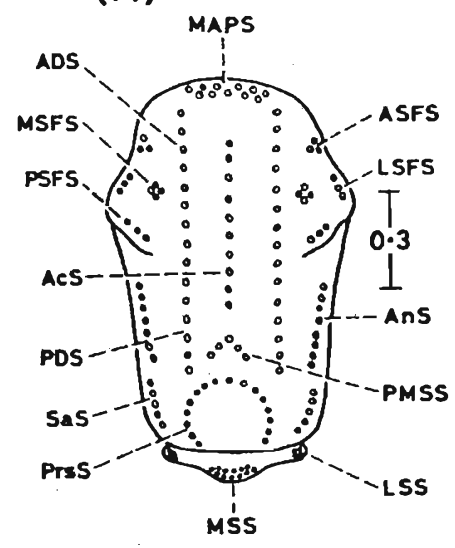

(B)

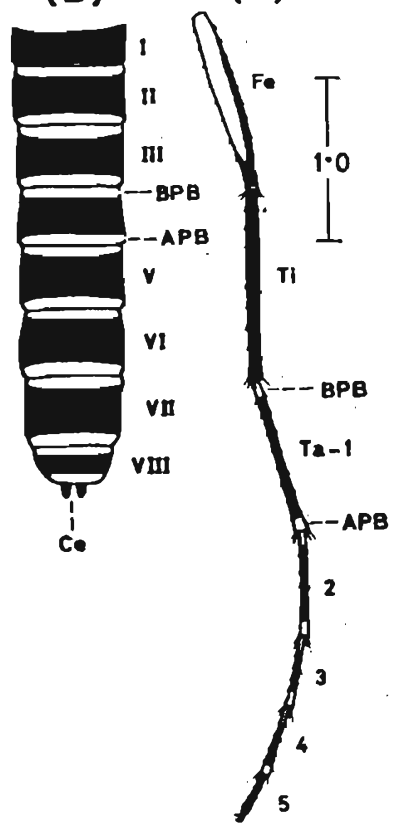



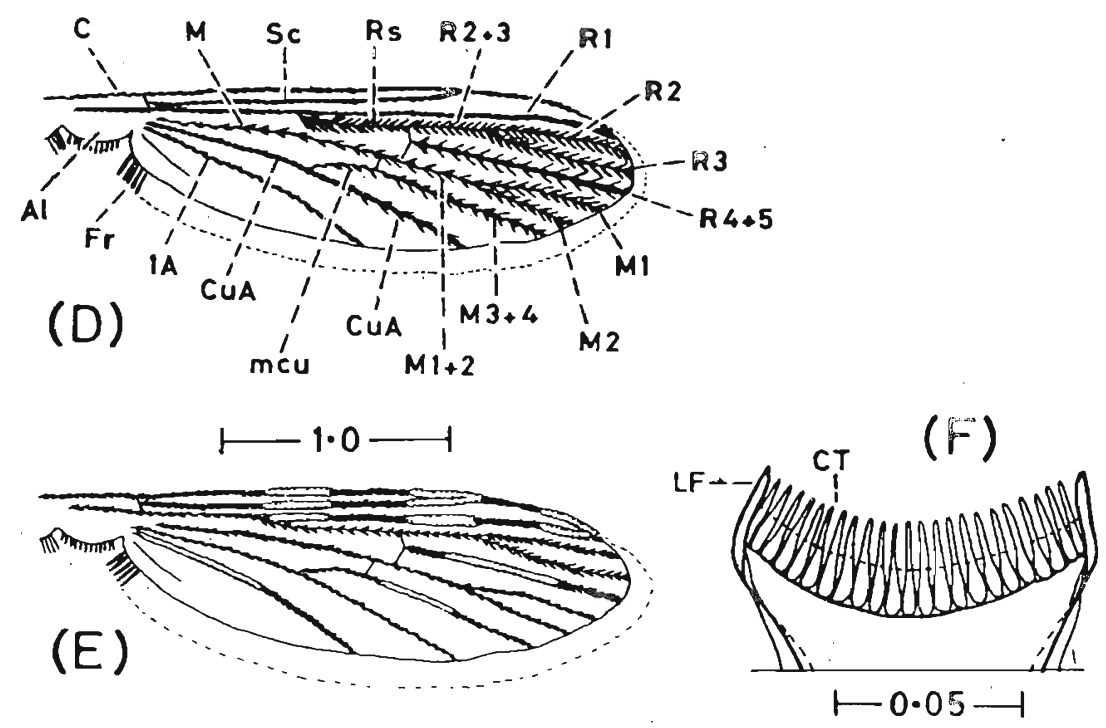

Figure 2: Generalized diagrams of a Culex mosquito. (A) Dorsal aspect of mesonotum; (B) Dorsal aspect of abdomen; (C) Anterior surface of hindleg; (D) Dorsal aspect of wing showing details of venation; (E) Dorsal aspect of wing with pale scale patches on veins; (F) Cibarial armature of female.

$\begin{array}{ll}\mathrm{AcS} & =\text { acrostichal seta } \\ \mathrm{ADS} & =\text { anterior dorsocentral seta } \\ \mathrm{Al} & =\text { alula } \\ \mathrm{AnS} & =\text { antealar seta } \\ \mathrm{APB} & =\text { apical pale band } \\ \mathrm{ASFS} & =\text { anterior scutal fossal seta } \\ \mathrm{A} & =\text { anal vein } \\ \mathrm{BPB} & =\text { basal pale band } \\ \mathrm{C} & =\text { costa } \\ \mathrm{Ce} & =\text { cerci } \\ \mathrm{CT} & =\text { cibarial teeth } \\ \mathrm{CuA} & =\text { cubitus anterior } \\ \mathrm{Fe} & =\text { femur } \\ \mathrm{Fr} & =\text { fringe } \\ \mathrm{LF} & =\text { lateral flange } \\ \mathrm{LSFS} & =\text { lateral scutal fossal seta } \\ \mathrm{LSS} & =\text { lateral scutellar seta } \\ \mathrm{M} & =\text { media } \\ \mathrm{MAPS} & =\text { median anterior promontory seta } \\ \text { mcu } & =\text { mediocubital crossvein } \\ \mathrm{MSFS} & =\text { median scutal fossal seta }\end{array}$

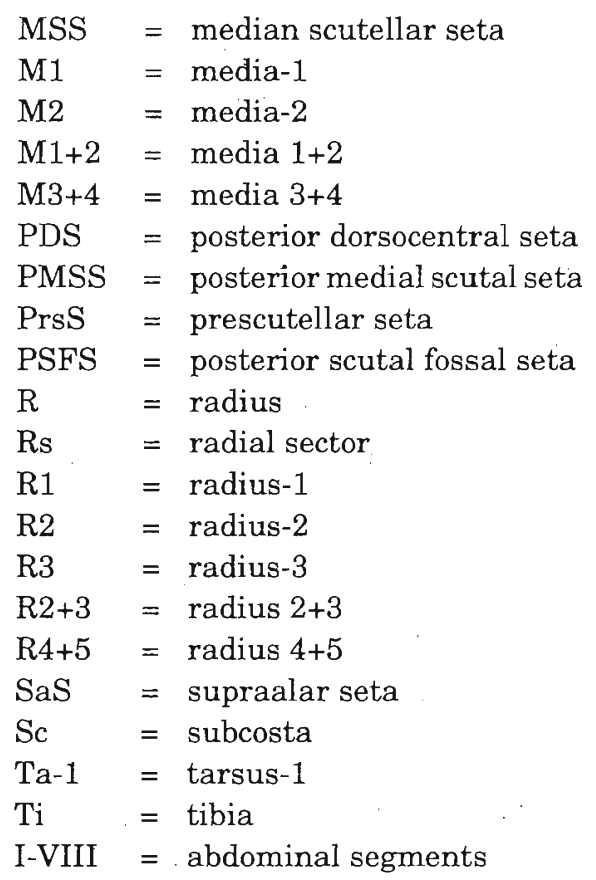


(A)

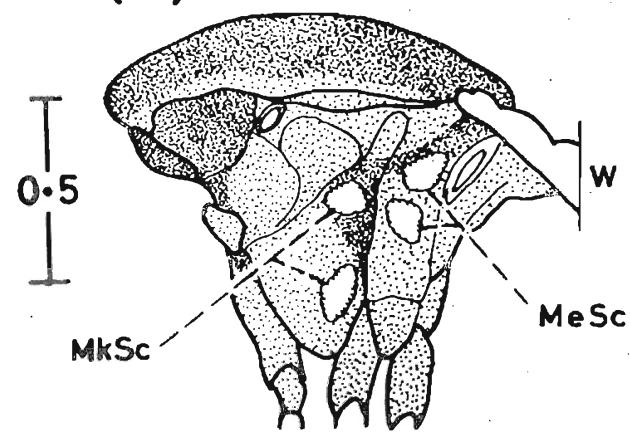

(B)

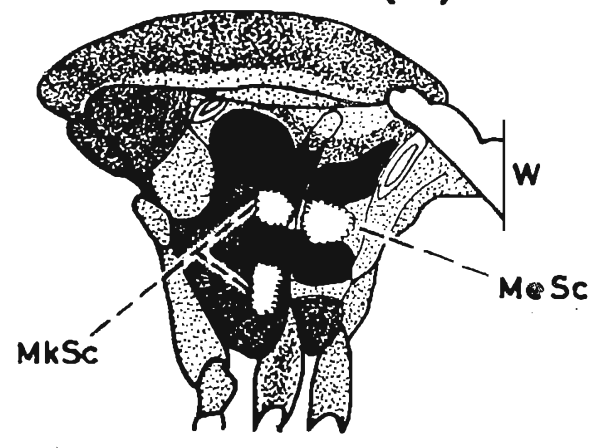

(D)

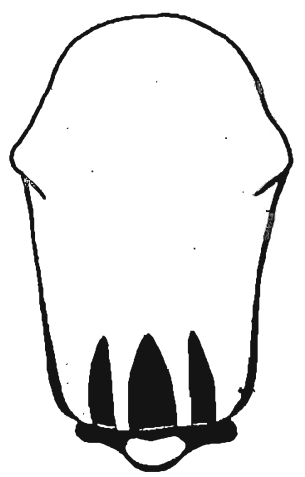

(F)

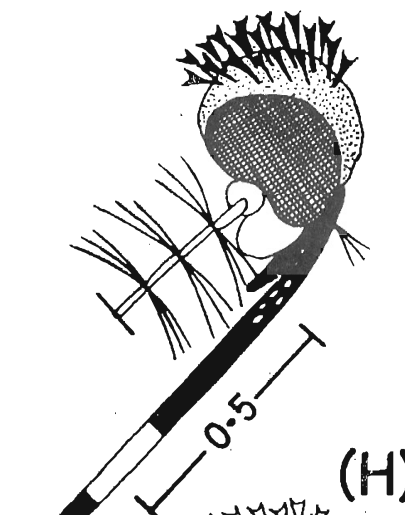

(H)

(G)
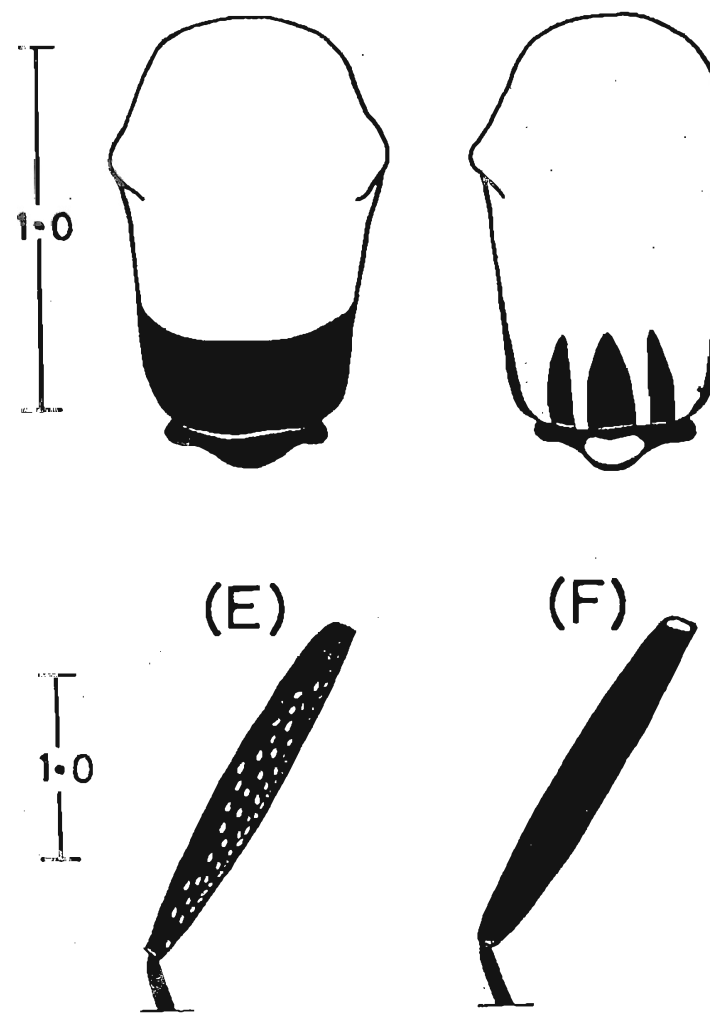
Figure. 3: (A) Lateral view of thorax of Cx. quinquefasciatus; (B) Lateral view of thorax of $\boldsymbol{C x}$. fuscocephala; (C) Dorsal view of mesonotum of $\boldsymbol{C x}$. gelidus showing area of white scalation; (D) Dorsal view of mesonotum of Cx. whitmorei showing area of white scalation; (E) Anterior surface of midfemur spotted with pale scales (drawn from $C x$. bitaeniorhynchus); (F) Anterior surface of dark-scaled midfemur (drawn from $\boldsymbol{C x}$. quinquefasciatus); (G) Lateral view of head with all dark erect scales on vertex and occiput (drawn from $C x$. tritaeniorhynchus); (H) Lateral view of head with a mixture of outer dark and central pale erect scales on vertex and ceciput drawn from Cx. pseudovishnui).

$$
\begin{aligned}
\mathrm{MeSc} & =\text { mesanepimeral scales } \\
\mathrm{MkSc} & =\text { mosokatepisternal scales } \\
\mathrm{W} & =\text { wing }
\end{aligned}
$$
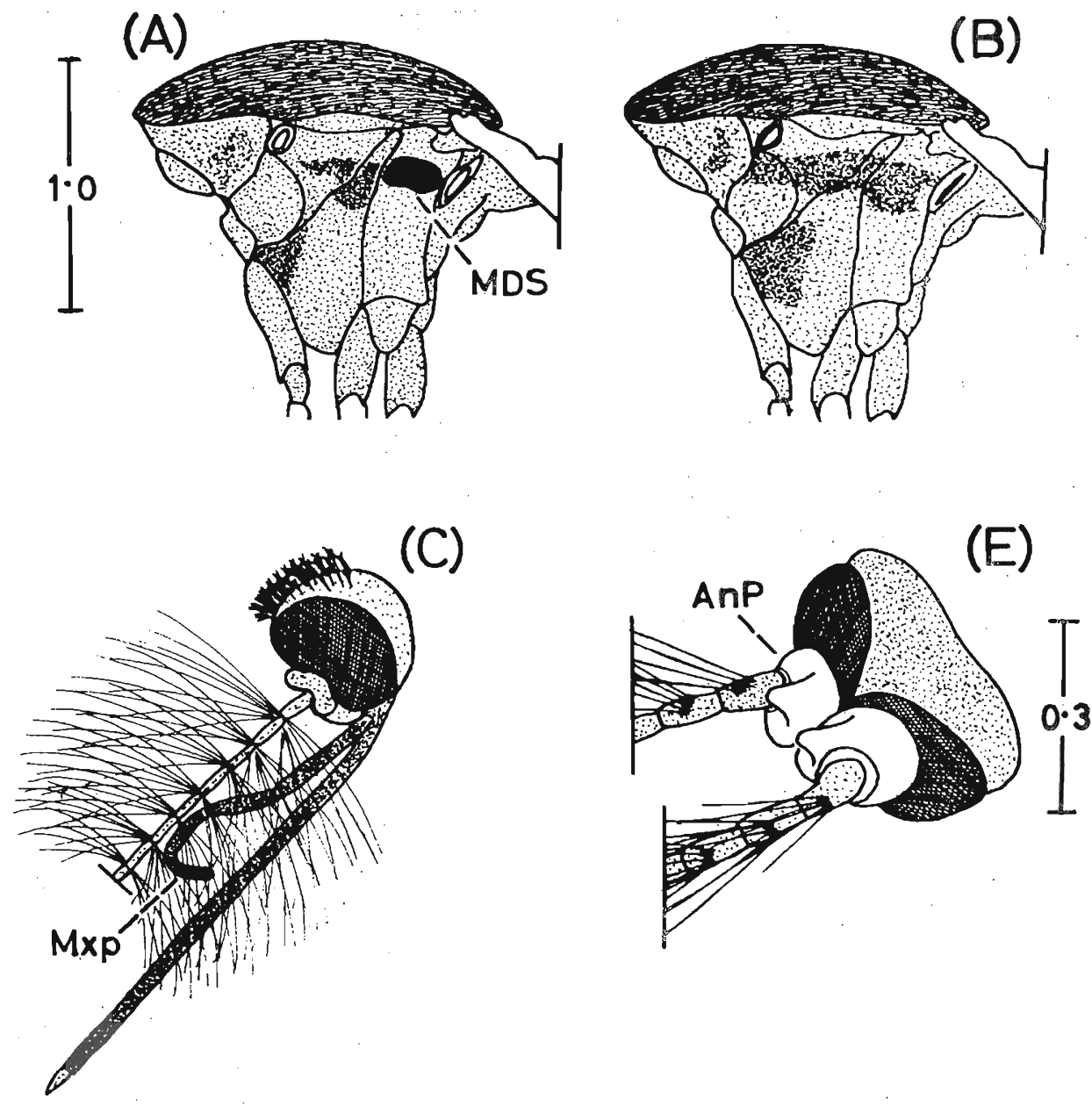


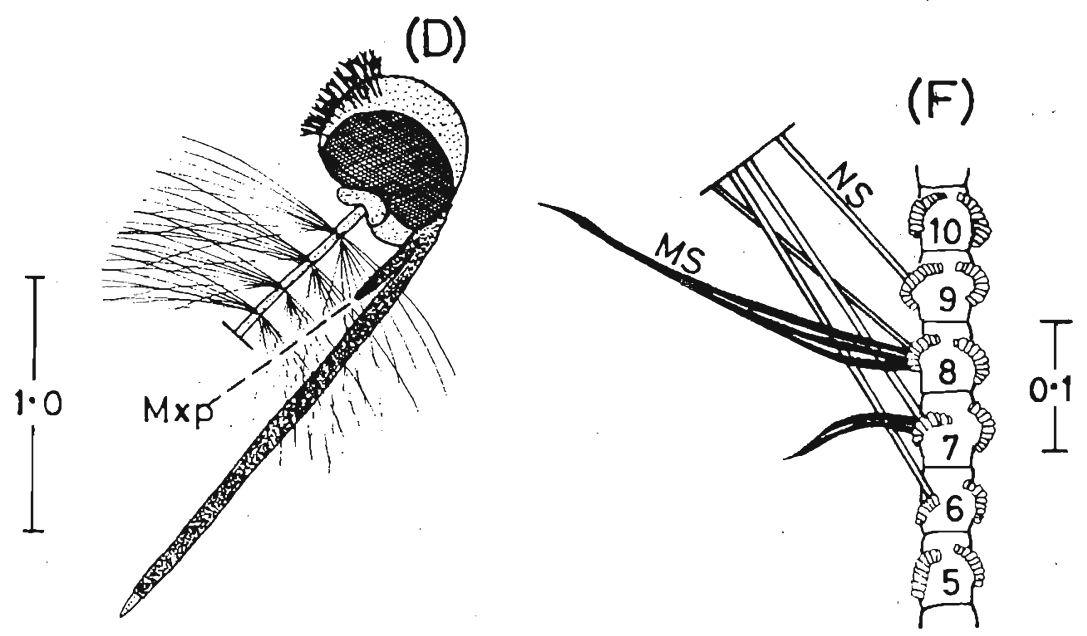

Figure 4: (A) Lateral view of thorax of Cx. nigropunctatus showing mesanepimeral dark spot; (B) Lateral view of thorax of $C x$. pallidothorax lacking mesanepimeral dark spot; (C) Lateral view of head of $C x$. brevipalpis male, showing maxillary palp; (D) Lateral view of head of Cx. malayi male, showing maxillary palp; (E) Dorsal view of head, showing spiculose prominence on antennal pedicel (drawn from $C x$. uniformis male); ( $F$ ) Normal and modified setae on male antennal flagellomeres 7-8 in subgenus.Lophoceraomyia (drawn from $C x$. minutissimus).

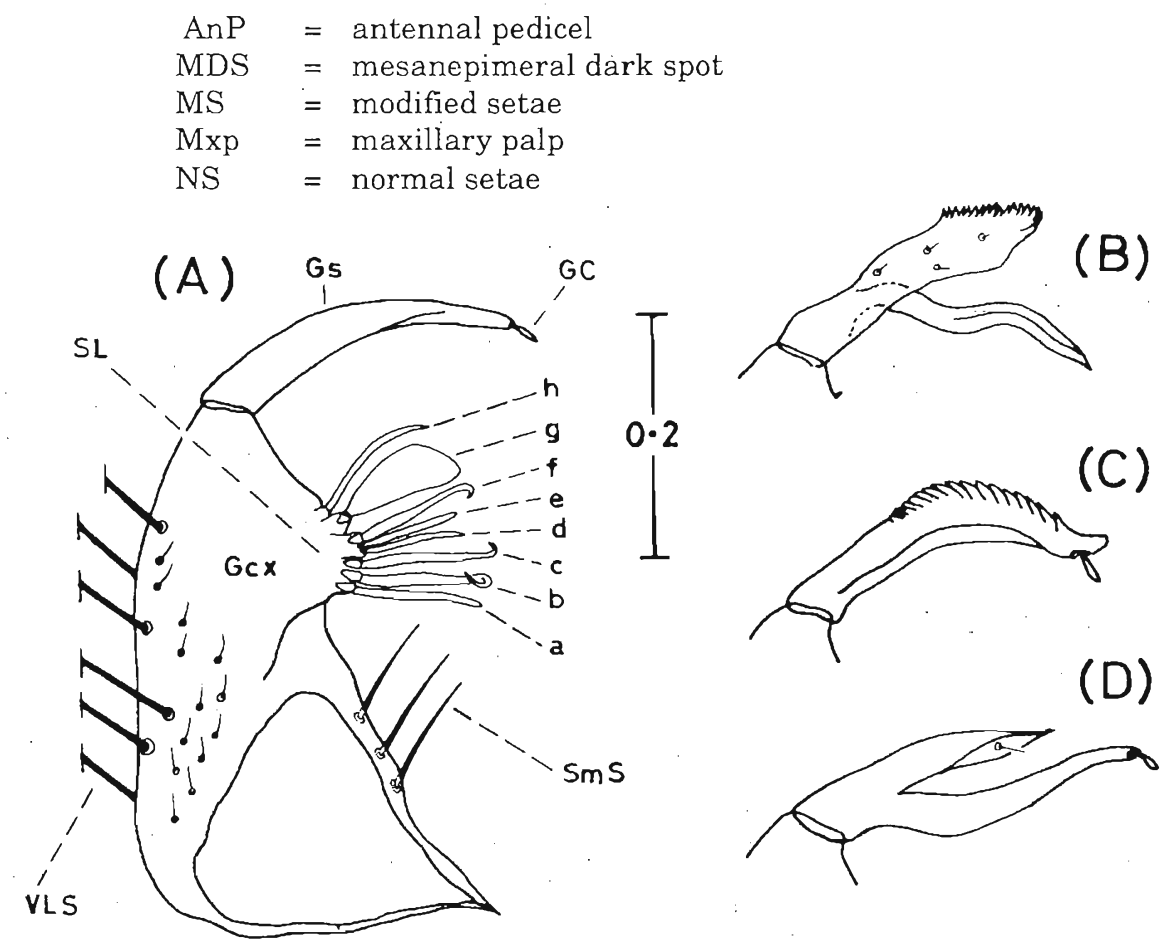




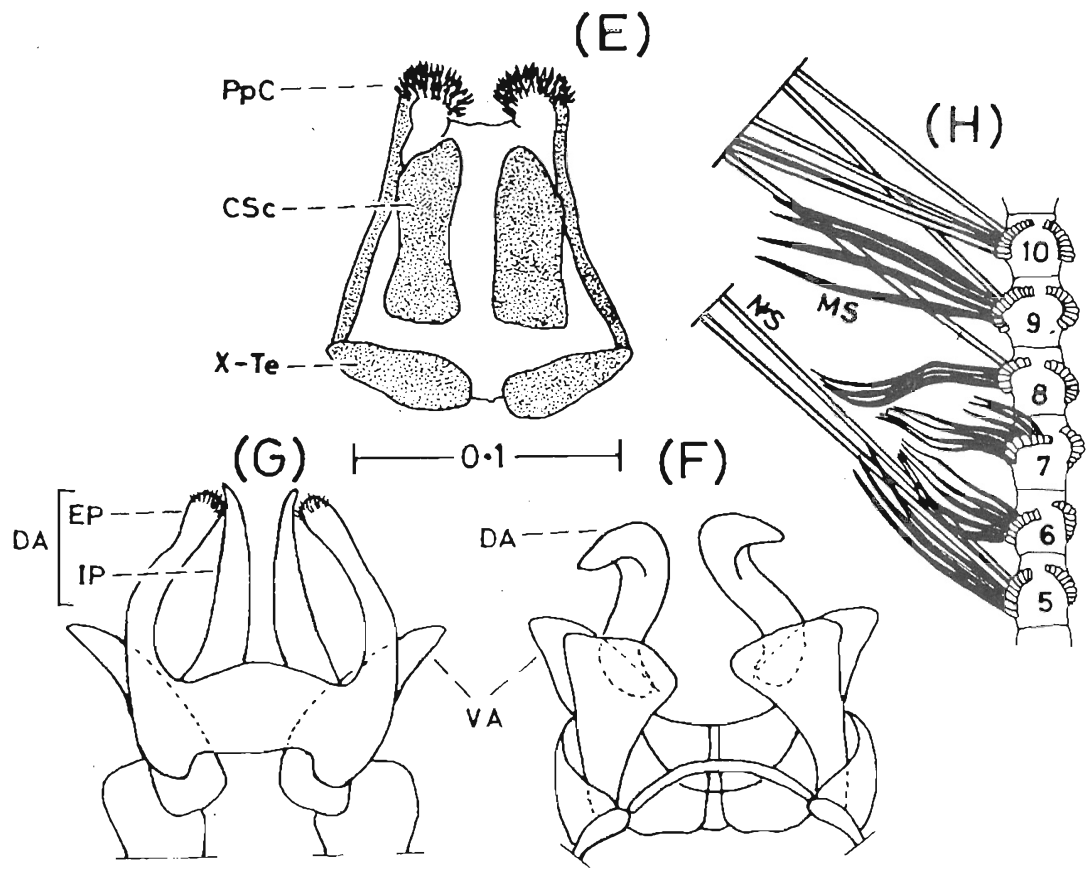

Figure 5: (A) Dorsal view (pre-rotation sense) of generalized Culex gonocoxite; (B) Characteristic bifurcate gonostylus of $C x$. spathifurca; (C) Gonostylus with crest of spines on convex margin (drawn from $C x$. fragilis); (D) Characteristic bifurcate gonostylus of Cx. malayi; (E) Dorsal view (pre-rotation sense) of generalized proctiger; (F) Dorsal view (pre-rotation sense) of phallosome with simple dorsal arm (drawn from Cx. minutissimus); (G) Dorsal view (pre-rotation sense) of phallosome with complex dorsal arm (drawn from $C x$. wardi); $(\mathrm{H})$ Normal and modified setae on male antennal flagellomeres 5-9 in subgenus Lophoceraomyia (drawn from Cx. wardi).

$\begin{aligned} \mathrm{a}-\mathrm{h} & =\text { setae } \mathrm{a}-\mathrm{h} \text { on subapical lobe } \\ \mathrm{CSc} & =\text { cercal sclerite } \\ \mathrm{DA} & =\text { dorsal arm } \\ \mathrm{EP} & =\text { external process } \\ \mathrm{GC} & =\text { gonostylar claw } \\ \mathrm{Gcx} & =\text { gonocoxite } \\ \mathrm{Gs} & =\text { gonostylus } \\ \mathrm{IP} & =\text { internal process }\end{aligned}$

$$
\begin{aligned}
\mathrm{MS} & =\text { modified setae } \\
\mathrm{NS} & =\text { normal setae } \\
\mathrm{PpC} & =\text { paraproct crown } \\
\mathrm{SL} & =\text { subapical lobe } \\
\mathrm{SmS} & =\text { submarginal seta } \\
\mathrm{VA} & =\text { ventral arm } \\
\mathrm{VLS} & =\text { ventral lateral seta } \\
\mathrm{X}-\mathrm{Te} & =\text { tergum-X }
\end{aligned}
$$




\section{References}

1. Amerasinghe F.P. (1991). A catalogue of the mosquitoes (Diptera : Culicidae) of Sri Lanka. Natural Resources Energy and Science Authority of Sri Lanka. $23 \mathrm{pp}$.

2. Carter H.F. (1948). Records of filaria infections in mosquitoes in Ceylon. Annals of Tropical Medicine and Parasitology 42: 312-321.

3. Sirivanakarn S. (1976). Medical entomology studies - III. A revision of the subgenus Culex in the Oriental region (Diptera: Culicidae). Contributions of the American Entomological Institute 12: 1-272.

4. Peiris J.S.M., Amerasinghe F.P., Amerasinghe P.H., Ratnayake C., Karunaratne S.H.P.P. \& Tsai T.F. (1992). Japanese encephalitis in Sri Lanka: the study of an epidemic vector incrimination, porcine infection and human disease. Transactions of the Royal Society of Tropical Medicine and Hygiene 86: 307-313.

5. Peiris J.S.M., Amerasinghe P.H., Amerasinghe F.P., Calisher C.H., Perera L.P., Arunagiri C.K., Munasingha N.B. \& Karunaratne S.H.P.P. (1994). Viruses isolated from mosquitoes collected in Sri Lanka. American Journal of Tropical Medicine \& Hygiene 51: 154-161.

6. Bram R.A. (1967). Contributions to the mosquito fauna of Southeast Asia. II. The genus Culex in Thailand (Diptera: Culicidae). Contributions of the American Entomological Institute 2: 1-296.

7. Sirivanakarn S. (1972). Contributions to the mosquito fauna of Southeast Asia. XIII. The genus Culex, subgenus Eumelanomyia in Southeast Asia and adjacent areas (Diptera: Culicidae). Contributions of the American Entomological Institute 8: 1-86.

8. Sirivanakarn S. (1975). The systematics of the Culex vishnui complex in Southeast Asia with the diagnosis of three common species (Diptera: Culicidae). Mosquito Systematics 7: 69-85.

9. Sirivanakarn S. (1977). Medical entomology studies - VI. A revision of the subgenus Lophoceraomyia of the genus Culex in the Oriental region (Diptera: Culicidae). Contributions of the American Entomological Institute 13: 1-245.

10. Sirivanakarn S. (1977). Redescription of four oriental species of Culex (Culiciomyia) and the description of a new species from Thailand (Diptera: Culicidae). Mosquito Systematics 9: 93-111.

11. Sirivanakarn S. (1977). A new species of Culex (Eumelanomyia) from India with descriptions of pupae and larvae of $C x$. pluvialis Barraud and $C x$. iphis Barraud (Diptera: Culicidae). Mosquito Systematics 9: 537-547. 
12. Barraud P.J. (1934). The Fauna of British India, including Ceylon and Burma. Diptera Vol. V. Family Culicidae. Tribes Megarhinini and Culicini. Taylor \& Francis, London. 463 pp.

13. Darsie R.F. \& Pradhan S.P. (1990). The mosquitoes of Nepal: their identification, distribution and biology. Mosquito Systematics 22: 69-130.

14. Edwards F.V. (1922). A synopsis of adult oriental culicine (including megarhinine and sabethine) mosquitoes. Part 1. Indian Journal of Medical Research 10: 249-293.

15. Thurman E.H.B. (1959). A contribution to a revision of the Culicidae of northern Thailand. Bulletin A-100, University of Maryland Agricultural Experimental Station. 186 pp.

16. Belkin J.N. (1962). The mosquitoes of the South Pacific (Diptera, Culicidae). University of California Press, Berkeley and Los Angeles. Vol. 1(608 pp.) and Vol. 2 (412 pp.).

17. Reuben R., Tewari S.C., Hiriyan J. \& Akiyama J. (1994). Illustrated keys to species of Culex (Culex) associated with Japanese encephalitis in Southeast Asia (Diptera: Culicidae). Mosquito Systematics 26: 75-96.

18. Harbach R.E. \& Knight K.L. (1980). Taxonomists' glossary of mosquito anatomy. Plexus Publishing Inc., New Jersey. 415 pp.

19. Harbach R.E. (1988). The mosquitoes of the subgenus Culex in Southwestern Asia and Egypt (Diptera: Culicidae). Contributions of the American Entomological Institute 24: 1-240. 